\title{
Krizlerle Baş Etmede Sosyal Medyanın Yeri ve Önemi
}

\author{
The Importance Of Social Media in Cope With Crisis
}

\author{
Aslı DIYADIN ${ }^{1}$, Tuncer ÖZDIL ${ }^{2}$
}

\begin{abstract}
ÖZET
Krizler, işletmelerin temel unsur ve yapıtaşları ile birlikte, bu kuruluşların finansal yapısına ve itibarına zarar veren olaylar olarak tanımlanabilir. Kriz yönetimi ise bu tür olayların olumsuz etkilerini gidermek veya azaltmaya ilişkin karar verme sanatıdır. Bu çalışmada sosyal medyada kriz yönetimi, gerçek hayatta ortaya çıkan olaylar üzerinden vaka analizi yardımıyla incelenmektedir. Araştırma kapsamında ele alınan örnek olaylar krizle karşı karşıya kalan işletmelerin, işletme içi ve işletme dışı iletişime önem vermeleri gerektiğini, kriz yönetimi stratejilerinde sosyal medya konusunda uzman paydaşların da bulunmasının yararlı olacağını açık bir şekilde göstermiştir.
\end{abstract}

Anahtar Kelimeler: Kriz, Kriz Yönetimi, Sosyal Medya

\section{GiRiş}

İnternetin gelişmesi ve sosyal medyanın öneminin artması ile bireyler kadar işletmeler tarafından da, sosyal medya bir iletişim aracı olarak kullanılmaya başlanmıştır. Kurumsal sayfalar vasıtasıyla sanal ortamda yer alan işletmeler, sosyal medyanın sağladığı; hız, ekonomiklik, verimlilik, zaman tasarrufu gibi birçok avantajdan yararlanabilmektedir. Ancak; sosyal medya, getirdiği avantajlarla birlikte işletmeler için önemli bir alan olsa da, oluşabilecek herhangi bir sorunda, işletmeyi krize de sürükleyebilir.

Çalışmamızda; gerçek hayatta oluşan, basın yayın organlarına yansıyan krizleri yaşamış, sosyal medyayı etkin olarak kullanan yerli ve yabancı 8 işletmenin, sosyal medya üzerinden yönettikleri kriz örnekleri, vaka analizi yöntemiyle incelenmiştir. $5 \mathrm{~N} 1 \mathrm{~K}$ ve SWOT analizi yardımıyla incelenen olaylar için, ortak faktörler oluşturulmaya çalışılmıştır. Bu faktörlerle, sosyal medyayı kullanan işletmelerin kriz yaşamamaları

\begin{abstract}
Crisis is any event that can harm institution's, its facilities, its finances or its reputation. Crisis management is the art of making decisions to head off or mitigate these kinds of effects. This study discusses the practical and research implications of social media in crisis management with several examples through the case studies. These cases clearly demonstrate that companies should exploit the inbound and outbound communication, networking, and collaboration capabilities of social media for including several other stakeholders into their crisis management strategies.
\end{abstract}

Key Words: Crisis, Crisis Management, Social Media

veya yaşayacakları bir krizle nasıl başa çıkacakları konusunda çıkarımlar yapılmaya çalışımıştır. Analizin 8 işletme üzerinden nitel araştırma teknikleriyle yapılması, konuyla ilgili yapılan literatür taraması sonucu teorik olarak tanımlanan 5 faktörün ayrıntılı olarak işlenmesinin ve özellikle Türkçe literatürde benzer çalışmaların azlığı dikkate alındığında çalışmanın taraflar için önemli katkılarının olabileceği düşünülmektedir.

\section{2. ÖRGÜTLERDE SOSYAL MEDYA KULLANIMI VE KRIZ YÖNETIMIYLE ILGILI LITERATÜR ARAŞTIRMASI}

Konuyla ilgili literatür incelendiğinde; sosyal medyada kriz yönetiminin öncesinde, sosyal medya ve işletmeler üzerine yapılmış çok sayıda çalışmaya rastlanmaktadır. Sosyal medya ile ilgili çalışmaların bir kısmı küçük ve orta ölçekli işletmelerle (kobi) ilgilidir. Bu çalışmalarda genel olarak; küçük işletmelerin gelişmeye açık olmasının yanında, sosyal medya kullanımı için, yeterli bilgi, eğitim ve çalışana 
sahip olmadıkları ifade edilmektedir (Humphreysa, Wilken, 2014; He, Wang, Chen, Zha, 2015; Bonson, Flores, 2011; Jones, Borgman ve Ulusoy, 2014; Wang, Pauleen, Zhang, 2015).

Kobiler dışında yapılmış ve sosyal medyayı içeren diğer çalışmaların çeşitlilik gösterdiği görülmektedir. Do, Ko ve Woodside (2015), Nike firmasının Tiger Woods ve Michelle Wie sponsorluğu inceleyerek, çalışmanın sonucunda, marka sponsorluğu, sosyal medya faaliyetleri ve tüketici arasındaki uyumun ve sosyal medya aktivitelerinin markanın müşterileri ile olan ilişkisi açısından önemli olduğunu ortaya çıkmıştır. Bir başka çalışmada, işletmelerin internette bulunmasının tüketiciler tarafından tercih edildiği ve işletmelerin sosyal medyada bulunmalarının, itibar ve işlevsellik ile ilişkili olduğu sonucu elde edilmiştir ( Ada ve Abul, 2014). Türkiye'deki futbol takımları üzerinde yapılan bir araştırmada da, Türkiye futbol ligi, Süper Toto Süper Lig'de yer alan futbol takımlarının sosyal medya kullanımları incelenerek, sosyal medyanın futbol takımları tarafından tutundurma aracı olarak kullanıldığı belirtilmektedir (Peltekoğlu ve Hürmeriç, 2012). Fortune 500 dergisinin 2010 yılı verilerine göre, "Türkiye'nin En Büyük 500 Firması" listesinde yer alan bilgi ve iletişim hizmetleri sağlayan 6 işletmenin incelendiği araştırmada 6 adet firmadan sadece ilk 3'ünün sosyal medyada aktif olduğu sonucuna ulaşılmıştır (Kara, 2012). Greer ve Ferugson (2011)'nun yerel televizyon istasyonlarının Twitter hesapları üzerinden yaptığı içerik analizinde, televizyon istasyonlarının Twitter takipçileri ile etkileşimde oldukları ve sadece haber yayını için değil, iletişim açısından da; Twitter'ın etkin olarak kullanıldığı anlaşılmıştır. Yapılan bu çalışmalarda da görüldüğü gibi sosyal medya araştırmaları birçok farklı alanda yürütülmektedir.

Sosyal medyada kriz yönetimi ile ilgili yapılan çalışmalar ise daha yeni ve sınırlıdır. Sosyal medyada yaşanan bir kriz geleneksel bir krize benzerlik gösterdiğinden, kriz yönetiminin temel ilkelerine bağlı kalınmakla birlikte, sosyal medyada kriz yönetim anlayışının sosyal medyaya uygun olarak revize edilmesi gerekmektedir. Bu yönetim anlayışında, sosyal medya temas edilecek ilk noktadır. Sosyal medya odaklı bir kriz, kuruluşlar, sosyal medya platformlarında artan negatif konuşmalar, geleneksel medya ilgisi, normal şirket operasyonlarının kesintiye uğraması gibi ek risklere maruz kalabilmektedir (Capozzi ve Rucci, 2013).
Andrews vd. (2016) yaptıkları araştırmada bir kriz anında sosyal medyada gerçek zamanlı yayılan haberlerin ve paylaşılan bilgilerin anlamlandırımasını incelemişlerdir. Hollanda'da yaşanan, bir kriz üzerine Twitter kullanıcılarının yorumlarının analiz edildiği bir çalışmada, fikirlerin hızla yayıldığı ve yanlış söylemlerin de aynı hızda yayılabileceği sonucuna ulaşılmıştır (Jong ve Dückers, 2016). Sosyal ağlar aracılığı ile ağızdan ağıza pazarlamanın etkileri Susarla ve Yong (2016) tarafından incelenmiştir. Graham ve Park (2015) yaptıkları çalışmada, yerel belediyelerin sosyal medyayı, kriz yönetimi ve kriz iletişimi aracı olarak nasıl kullandıklarını incelemiştir. Kim, Zhang ve Zhang (2016), sosyal medya kullanılarak, mizah yoluyla kriz yönetimi yapılması süreci çalışıımıştır. Sina Weibo sosyal medya sitesi üzerinden yapılan, iki rakip markanın tartışmasının metinsel analiz yöntemiyle incelendiği bir çalışmada, sempatinin marka imajını düzeltmede etkili olduğu sonucuna ulaşılmıştır ( Wang, 2016). Hsu ve Lawrence (2016) 'ın yaptığı çalışmada, bir ürünün geri çağırılmasının marka üzerindeki etkisi sosyal medya üzerinden incelenerek ürünleri geri çağırmanın işletmeler üzerinde olumsuz bir etkisi olduğu sonucuna ulaşılmıştır. Zhao, Yin ve Song (2016), kriz dönemlerinde sosyal medya kullanıcılarının davranışlarını incelenmiştir. Kriz iletişiminde sosyal medyanın rolünün incelendiği başka bir çalışmada ise, kriz iletişimini geliştirmek için öneriler ve yaklaşımlar sunulmuştur (Lin vd., 2016). Ryschka vd. (2016), Bir kriz anında itibarın sosyal medya aracılığıyla hangi yönde değiştiği incelenmiştir. Sandy kasırgası sırasında, Twitter verilerinin incelenmesiyle, sosyal medyada krizlerin hızla yayıldığı görülmüştür (Yoo vd., 2016). Omilion-Hodges ve McClain (2016) üniversitelerde kriz anında sosyal medya hesaplarının nasıl kullanıldığına ilişkin bir çalışma yapılmıştır. Başka bir çalışmada yerel yönetimler açısından, kriz yönetimi aracı olarak sosyal medya kullanımı incelenmiştir ( Graham vd. 2015). Gruber vd. (2015), Twitter kullanılarak, çağdaş iş ortamında kriz yönetimi ile ilgili çıkarımlar yapmaya çalışılmıştır. Maresh-Fuehrer ve Smith (2015) yaptıkları çalışmada kriz yönetiminde sosyal medya kullanımı sosyal medya haritalama uygulamaları ile açıklanmaktadır. Alexander, (2014), afetlerin sebep olduğu kriz durumunda, sosyal medyanın kullanımı ele alınmıştır.

Sosyal medya- kriz ilişkisinin araştırıldığı çalışmalar genel olarak değerlendirildiğinde, son yıllarda yapılan çalışmaların; yerel yönetimlerde ve doğal afetlerde yaşanan krizlerin sosyal medya kullanılarak çözümü, Twitter gibi sosyal ağların kriz yönetim süre- 
cine etkileri, sosyal medya haritalama uygulamaları, sosyal medyanın firma itibarına etkisi, kriz anında sosyal medya kullanıcılarının davranışları, sosyal medyada mizahi açıdan krizle başetme gibi konular üzerinde yoğunlaştığı görülmektedir.

Günümüzde sosyal medya işletmeler için yadsınamaz temel bir faaliyet alanıdır. İşletmeler sosyal medyayı dışlamak yerine tam tersi sosyal medyayla iç içe olmanın yollarını aramalıdırlar. Artık işletmeler ürettikleri ürünlerin tanıımından satışına kadar hemen hemen tüm faaliyetlerini sosyal medya üzerinden gerçekleştirebilmektedirler. Böyle bir süreç beraberinde işletmeler için önemli ölçüde maliyet ve zaman avantajı sağlarken zaman zaman olumsuz olarak işletmelerin krizlerle de karşılaşmalarına veya karşılaştıkları krizlerin etkisinin daha artarak hızla yayılmasına neden olabilmektedir.

\section{METODOLOJi}

Krizlerle baş etmede sosyal medyanın rolünü açıklayabilmek için hem ülkemizden hem dünyadan başarılı-başarısız gerçek kriz vakaları incelenmiştir. Araştırmaya konu sekiz kriz vakasının incelenmesi içerik analizi yardımıyla yapılmıştır.

Araştırma kapsamına, çalışmanın hazırlandığı dönemde (2015) sosyal medya en fazla yer alan, sosyal medyada başlayan, sosyal medya üzerinden yürütülen ve kriz yönetim süreciyle ilgili veri elde edilebilme kriterlerine uygun olarak işletmeler seçilmiştir. Bu bağlamda toplam sekiz adet işletme araştırma kapsamına dahil edilmiştir.

Çalışmaya dahil edilen sekiz işletmenin sosyal medya üzerinden yönettikleri kriz yönetim stratejileri araştırılmış ve bu kapsamda işletmelerin sosyal medya üzerinden etkili kriz yönetmelerini sağlayacak ortak faktörler elde edilmeye çalışıımıştır. Araştırma özellikleri bakımından keşifsel bir nitelik taşımaktadır. Bu amaçla, öncelikle ilgili işletmeler hakkında genel bilgiler elde edilerek, ardından bu işletmelerin sosyal medya da yaşadıkları kriz ve uyguladıkları stratejiler ayrıntılı olarak incelenmiştir. Son aşamada ise bu işletmelerin kriz yönetme süreçleri, hız, kurumsal imaj, geri bildirim araçları, iletişim ve sosyal medya becerisi unsurları bakımından ayrıntılı olarak değerlendirilmeye çalışılmıştır.

\subsection{Veri Toplama ve Analiz}

Kurumlar arasında karşılaştırma yapabilmek ve ilgili firmaları çeşitli açılardan değerlendirebilmek için tüm firmaların yaşadıkları krizlerin bir arada yer aldığı tablo 2 düzenlenmiştir. Sözkonusu tablo, Aktan (2006)'nın çalışmasında kullanılan 5N1K yöntemi kullanılarak oluşturulmuştur. 


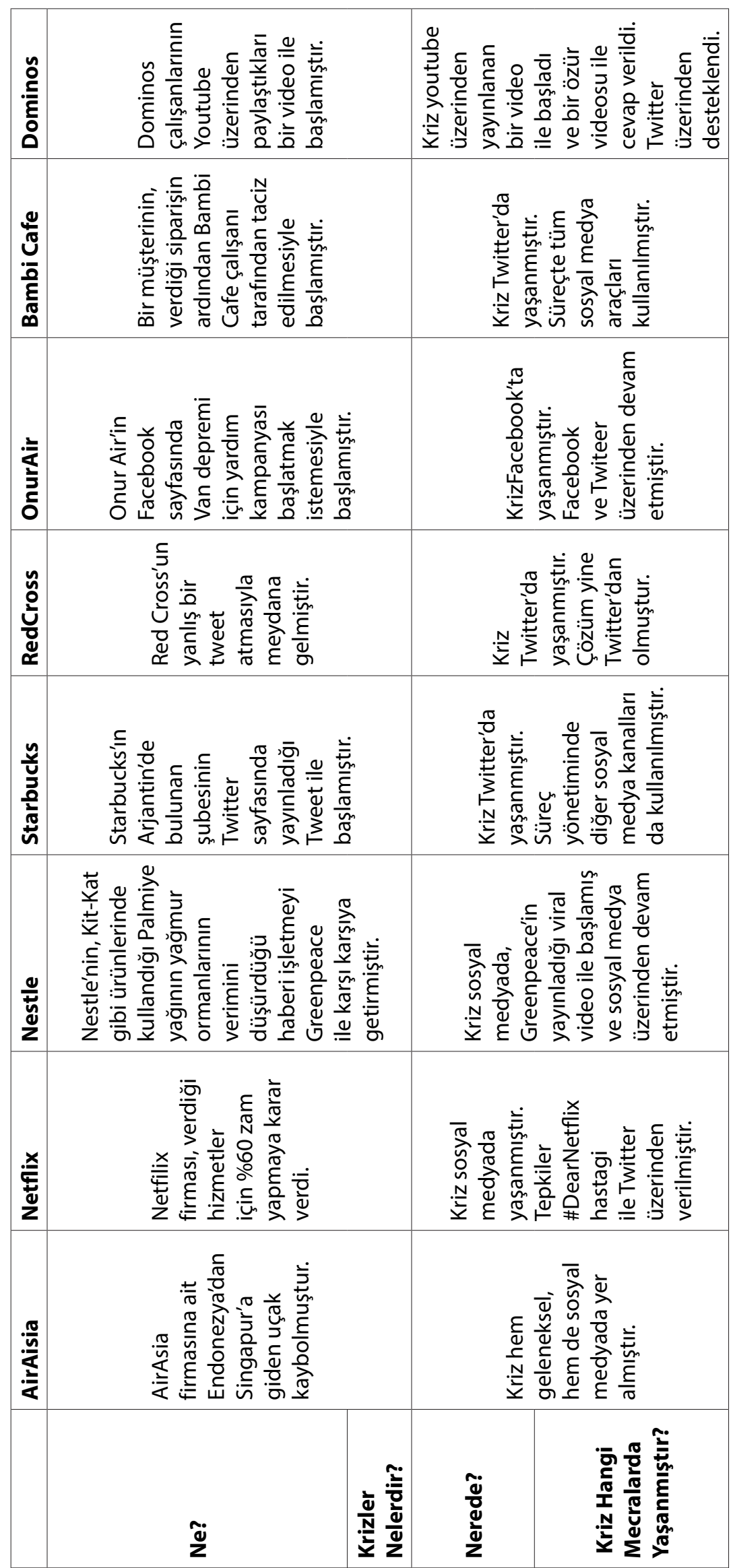




\begin{tabular}{|c|c|c|c|c|}
\hline 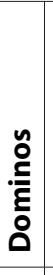 & 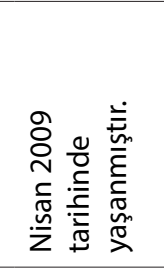 & & 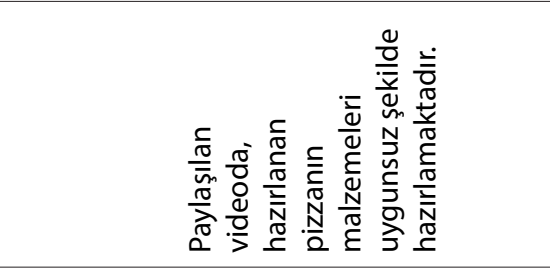 & \\
\hline 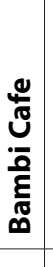 & 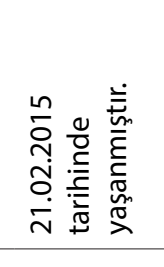 & & 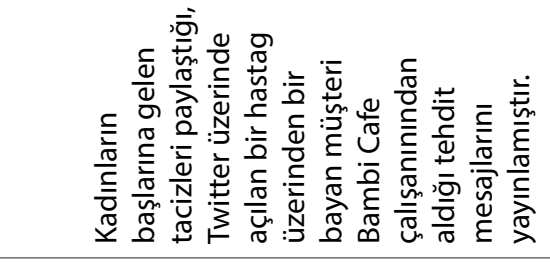 & \\
\hline 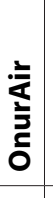 & 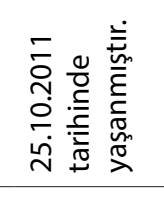 & & 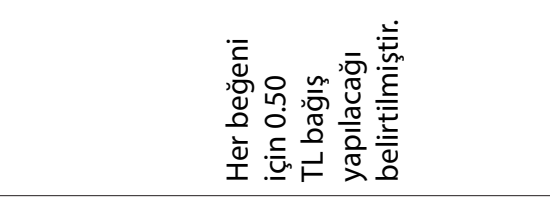 & \\
\hline 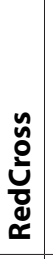 & 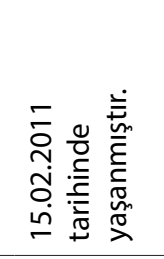 & & 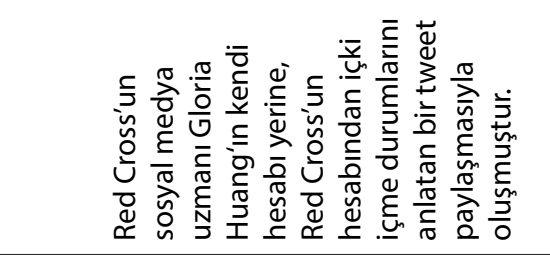 & \\
\hline 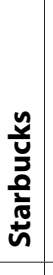 & 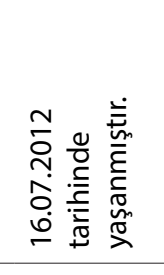 & & 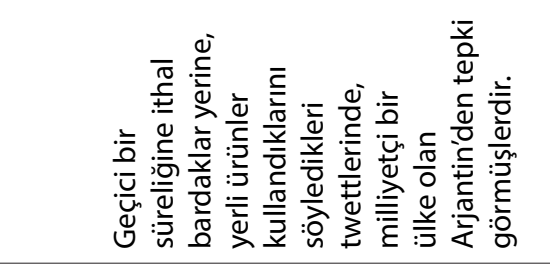 & \\
\hline 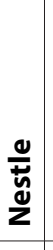 & 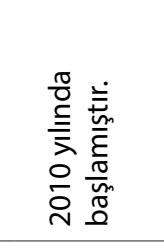 & & 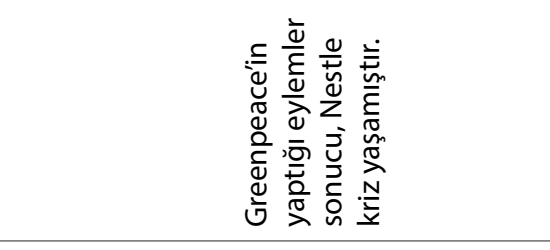 & \\
\hline 﨎 & 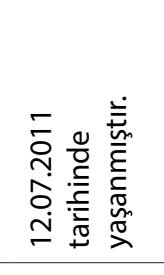 & & 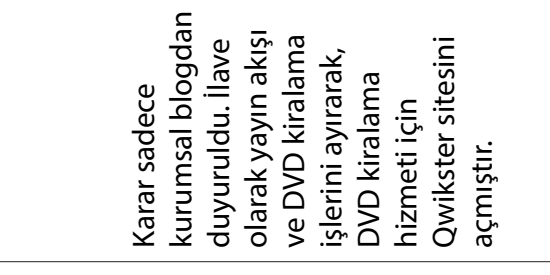 & \\
\hline 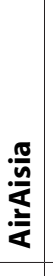 & 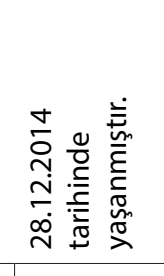 & & 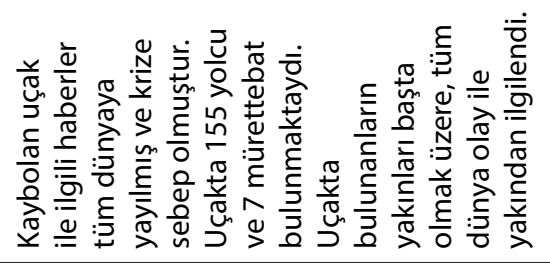 & \\
\hline & 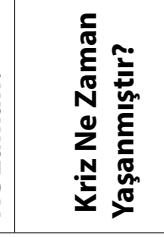 & $\stackrel{\tilde{E}}{\underline{\tilde{z}}}$ & $\begin{array}{l}\tilde{\tilde{g}} \\
\tilde{\tilde{g}} \\
\tilde{z}\end{array}$ & 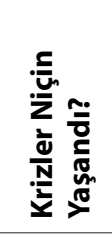 \\
\hline
\end{tabular}




\begin{tabular}{|c|c|c|c|}
\hline .气 & 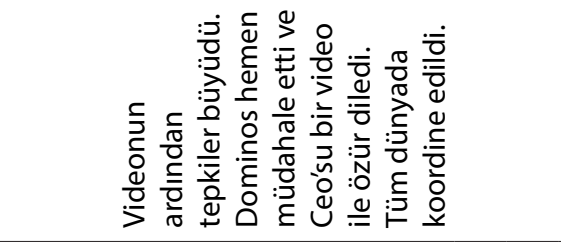 & \multicolumn{2}{|c|}{ 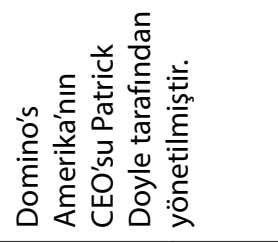 } \\
\hline 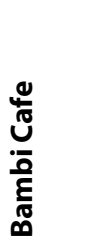 & 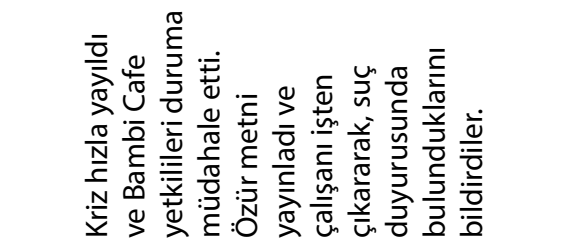 & \multicolumn{2}{|c|}{ 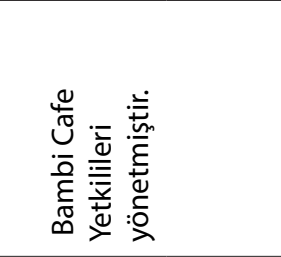 } \\
\hline 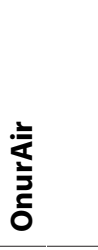 & 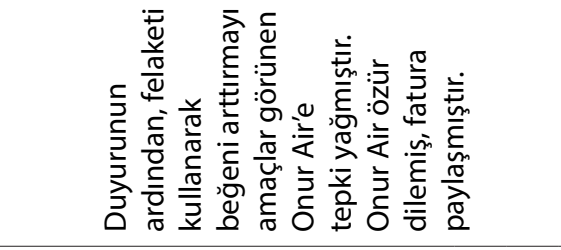 & \multicolumn{2}{|c|}{ 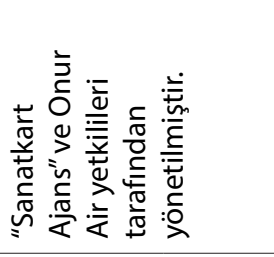 } \\
\hline 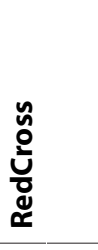 & 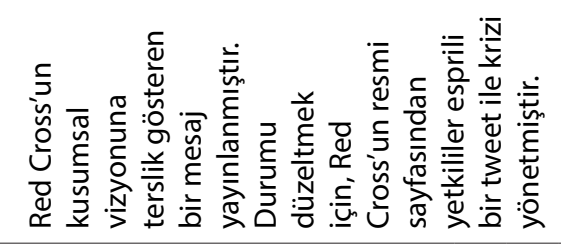 & \multicolumn{2}{|c|}{ 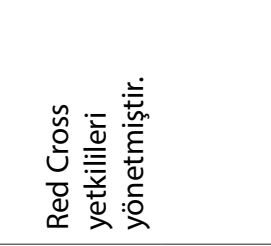 } \\
\hline 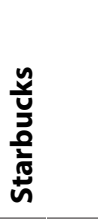 & 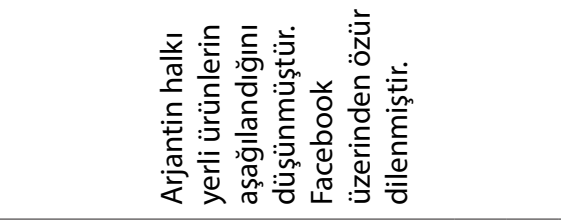 & \multicolumn{2}{|c|}{ 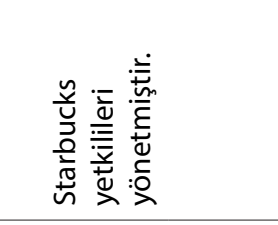 } \\
\hline 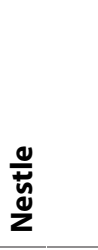 & 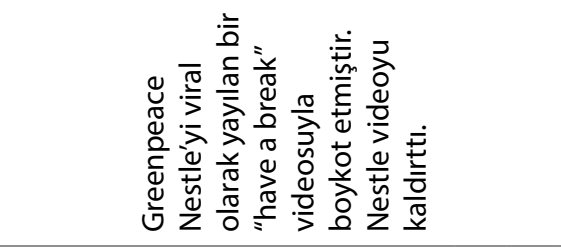 & \multicolumn{2}{|c|}{ 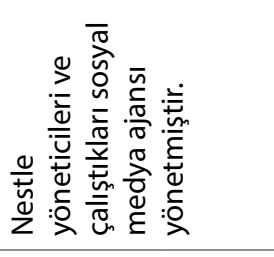 } \\
\hline $\begin{array}{l}\text { 堅 } \\
\mathbf{e}\end{array}$ & 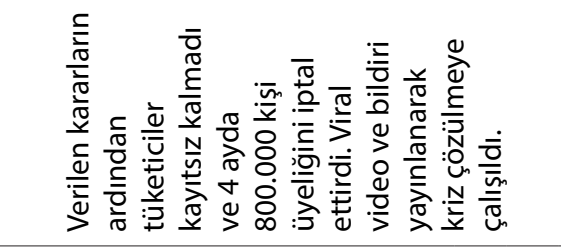 & \multicolumn{2}{|c|}{ 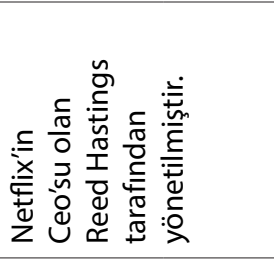 } \\
\hline 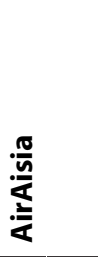 & 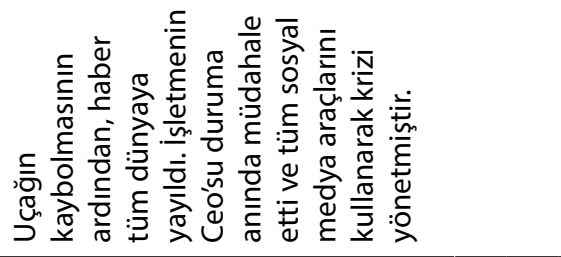 & \multicolumn{2}{|c|}{ 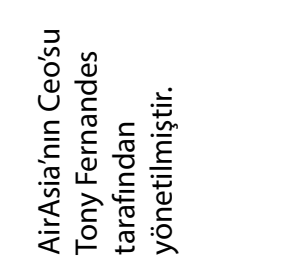 } \\
\hline 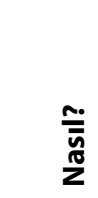 & 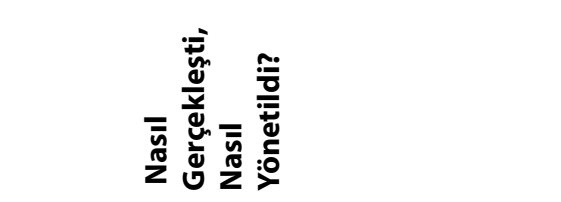 & $\underset{\underline{\underline{\xi}}}{\tilde{\underline{x}}}$ & ث̃ \\
\hline
\end{tabular}


Tablo 2'in incelenmesiyle de anlaşılacağı gibi, tüm işletmelerde krizlerin başlangıcı ve kriz yönetimi süreci sosyal medya üzerinde gerçekleşmiştir. Bu noktada işletmeler krizle mücadele süreçlerinde Facebook, Twitter ve kendi kurumsal web sayfalarını etkin olarak kullanmışlardır. Bu sekiz firmanın karşılaştıkları krizlerin ve kriz yönetim süreçlerinin önceden tanımlanan beş ana unsur bakımından değerlendirme sonuçları tablo 3'de gösterilmektedir.

Tablo 3: Krize Illişkin Çeşitli Faktörler Bakımından Iş̧letmelerin Değerlendirilmesi

\begin{tabular}{|l|l|l|l|}
\hline Faktörler & $\begin{array}{l}\text { Başarılı } \\
\text { İşletmeler }\end{array}$ & $\begin{array}{l}\text { Başarısız } \\
\text { İşletmeler }\end{array}$ & Sonuç \\
\hline Hız & $\begin{array}{l}\text { AirAsia, Starbucks, Bambi } \\
\text { Cafe, Dominos, Redcross }\end{array}$ & $\begin{array}{l}\text { Netflix, Nestle, } \\
\text { Onur Air }\end{array}$ & $\begin{array}{l}\text { Kriz anında yeterince hızlı olmayı başarabilen } \\
\text { işletmeler erken uyarı sistemlerinin de } \\
\text { yardımıyla krizi daha kısa sürede atlatabilir. }\end{array}$ \\
\hline Geri Bildirim Araçları & $\begin{array}{l}\text { AirAsia, Redcross, } \\
\text { Starbucks, Bambi Cafe, } \\
\text { Dominos }\end{array}$ & $\begin{array}{l}\text { Netflix, Nestle, } \\
\text { Onur Air }\end{array}$ & $\begin{array}{l}\text { Geri bildirim araçlarını kullanmakta başarılı } \\
\text { olan işletmeler mevcut ve olası krizlere daha } \\
\text { hızlı tepkiler verebilir. }\end{array}$ \\
\hline Iletişim & $\begin{array}{l}\text { AirAsia, Redcross, } \\
\text { Starbucks, Bambi Cafe, } \\
\text { Dominos }\end{array}$ & $\begin{array}{l}\text { Netflix, Nestle, } \\
\text { Onur Air }\end{array}$ & $\begin{array}{l}\text { Krizlere müdahale noktasında gerek kurum } \\
\text { içi gerekse kurum dışı iletişime önem veren } \\
\text { işletmeler diğerlerine göre daha etkin bir kriz } \\
\text { yönetimi sergilemişlerdir. }\end{array}$ \\
\hline Sosyal Medya Becerisi & $\begin{array}{l}\text { AirAsia, Redcross, Bambi } \\
\text { Cafe, Dominos }\end{array}$ & $\begin{array}{l}\text { Netflix, Nestle, } \\
\text { Onur Air, } \\
\text { Starbucks }\end{array}$ & $\begin{array}{l}\text { İşletmelerin sosyal medyayı kullanabilmelerine } \\
\text { ilişkin becerileri, krizi başarılı bir şekilde } \\
\text { atlatabilmelerini sağlamıştır. }\end{array}$ \\
\hline Kurumsal İmaj & $\begin{array}{l}\text { AirAsia, Starbucks, } \\
\text { Redcross, Bambi Cafe, } \\
\text { Dominos }\end{array}$ & $\begin{array}{l}\text { Netflix, Nestle, } \\
\text { Onur Air }\end{array}$ & $\begin{array}{l}\text { Tüm bu faktörler noktasında başarılı olan } \\
\text { işletmeler, krize bağlı olarak kurumsal } \\
\text { imajlarına gelebilecek zararı kısmen de olsa } \\
\text { engellemiş olurlar. }\end{array}$ \\
\hline
\end{tabular}

Genel verilerin daha iyi sonuç vermesi için, veriler sayısallaştırılmak istenmiştir. Sayısallaştırma her faktör için ortak bir değer üzerinden yapılmak istenmiştir. Kriz yönetimi sürecinde, her faktör için pozitif yönlü ivme gösteren faktöre +1 , negatif yönlü ivme gösteren faktöre ise -1 verilmiştir.

Hız için;

- Hızlı geri dönüş +1

- Yavaşgeri dönüş-1

Kurumsal imaj için;

- Kurumsal imajın zedelenmemesi +1

- Kurumsal imajın zedelenmesi -1

Geri bildirim araçları için;
- Geri bildirimde kullanılan sosyal medya araçları yeterli +1

- Geri bildirimde kullanılan sosyal medya araçları yetersiz -1

Illetişim için;

- Yeterli iletişim +1

- Yetersiz iletişim -1

Sosyal medya becerisi için;

- Sosyal medya kullanım becerisi yeterli +1

- Sosyal medya kullanım becerisi yetersiz-1

Yapılan puanlama sonuçları şu şekildedir: 
Tablo 4: Genel Değerlendirme

\begin{tabular}{|c|c|c|c|c|c|c|}
\hline & \multirow[b]{2}{*}{ Hız } & Kurumsal & \multirow{2}{*}{ Geri Bildirim } & \multirow[b]{2}{*}{ İletişim } & Sosyal & \multirow[b]{2}{*}{ Toplam } \\
\hline & & \multirow{2}{*}{ İmaj } & & & Medya & \\
\hline & & & Araçları & & Becerisi & \\
\hline AirAsia & +1 & +1 & +1 & +1 & +1 & +5 \\
\hline Netflix & -1 & -1 & -1 & -1 & -1 & -5 \\
\hline Nestle & -1 & -1 & -1 & -1 & -1 & -5 \\
\hline Starbucks & +1 & -1 & +1 & +1 & -1 & +1 \\
\hline Redcross & +1 & +1 & +1 & +1 & +1 & +5 \\
\hline Onur Air & -1 & -1 & -1 & -1 & -1 & -5 \\
\hline Bambi Cafe & +1 & +1 & +1 & +1 & +1 & +5 \\
\hline Dominos & +1 & +1 & +1 & +1 & +1 & +5 \\
\hline
\end{tabular}

Tablo 4'de yer alan sonuçlar incelendiğinde ilk göze çarpanın, kriz sürecini en başından iyi yöneten bir firmanın, süreç boyunca olumlu puanla ilerlemesidir. Bir faktörde başarı gösteren bir firma diğer faktörlerde de başarı göstermiştir diyebiliriz. Toplam puanlar incelendiğinde 8 firmadan, 7 firma bu sonucu desteklemekte olup ilgili süreçteki faktörlerin birbiri ile ilişkili olduğunu ve faktörlerin birinden etkilendiğini söyleyebiliriz.

AirAsia, Red Cross, Bambi Cafe ve Dominos +5 puanla, sosyal medya kriz sürecini iyi yöneten firmalardır. Süreçte yaşanan krizler AirAsia, Dominos ve Red Cross için işletmelerinde ciddi kayıplara yol açabilecek büyük montanlı krizlerdir. Bu firmaların süreci iyi yöneterek +5 puan elde etmelerinde, incelediğimiz ilk faktör olan hız etkili olmuştur. Kriz ortaya çıktığı anda, hızlı müdahale kriz sürecine pozitif bir başlangıç yapılmasını sağlamıştır. Hızlı müdahalenin ardından, diğer faktörlerde doğru yönetilerek domino etkisi elde edilmiştir.

Netflix, Nestle ve Onur Air firmaları süreci -5 puan ile sonuçlandırmıştır. Domino etkisinin bu üç firma için de geçerli olduğunu düşündüğümüzde, hızlı davranılmadığı görülmektedir. Yavaş kalınması diğer faktörlerin de olumsuz devam etmesine sebep olmuştur.

İstisna olarak süreci +1 puanla tamamlayan Starbucks firması, sürece müdahalede hızlı davranmıştır. Ancak sosyal medya becerisinin yetersiz olması, krizin kurumsal imajını zedelemesine sebep olmuştur.

Seçilen sekiz firma kriz yönetimi sürecinde sosyal medyayı kullanmış ve kriz dönemlerini bu yolla yönetmişlerdir. Yapılan değerlendirme sonucunda, kriz yönetiminin sosyal medya üzerinden yapılması durumu SWOT analizi yolu ile incelenecektir.

SWOT analizi İngilizce Strengh (güçlü), Weakness (zayıf), Opportunity (fırsat) ve Threat (tehdit) kelimelerinin baş harflerinden oluşmaktır. SWOT analizi yaparken, bir firmanın bulunduğu durum ile ilgili karşılaşabileceği tehdit ve fırsatları ve bu durum karşısındaki güçlü zayıf yönlerini bir arada göstermektedir. Sosyal medyayı aktif olarak kullanan bir işletmenin kriz yönetimi sürecindeki SWOT analizi aşağıdaki gibidir: 
Güçlü Yönler

Uzman bir soysal medya ekibinin

olmas1 Güçlü ekonomik yap1

Doğru iletişim dili

Kriz planınin var olmas1

Rakipleri analizinin kolay olmasi
S W

Uzmanlardan yararlanmama

Ekonomik yetersizlik

Sosyal medya dilinde eksiklik

Kriz planinın olmaması ve panik

Rakipleri gözlemlememe kolaylığı

\section{T}

\section{Tehditler}

Sosyal medyayı takip etme zordur

Anında binlerce kişiye yayılabilir.

Diyalog kurulması firsatı verilmeyebilir.

Yanlış anlaşılmalara sebep olabilir. Olası

hatalar, itibarı zedeleyebilir.

Verilen mesajın yanlış anlaşılabilir.

\section{İstenilen kitleye hızlı ulaşım sağlar}

Şekil 1: Sosyal Medyada Kriz Yönetiminde SWOT Analizi

Analiz sonucunda sosyal medyanın kriz yönetimi sürecinde birçok fayda ve fırsat sağlamasının yanı sıra, işletmeler için güçlük ve zayıflık getirdiği de görülmektedir.

Burada işletmelerin zayıf oldukları yönlerini görmeleri ve bu bağlamda eksikliklerini gidermeleri gerekirken, öte yandan güçlü yönlerini korumalı ve bunları fırsata çevirmelidir.

Bir kurumun kendi içinde SWOT analizi yapması, kurumu dışarıdan gelen tehditlere karşı korur ve kurum için faktörleri geliştirmesine yardımcı olur. SWOT analizi ile kurumlar mevcut durumlarını belirler ve gelecek durumlar için bir plan oluşturabilir.

$\mathrm{Bu}$ analizle öncelikli olarak sosyal medyanın onlara sunduğu fırsatları net bir şekilde görebilecek ve bu fırsatlardan nasıl yararlanacaklarına karar verebileceklerdir. Sosyal medyanın sağladığı fırsatlara karşılık olarak, bu alanda karşılaşılabilecek tehditlerin açık bir şekilde görülmesi yine SWOT analizi ile mümkün olmaktadır. Böylelikle, işletmeler bu tehditlere karşı önlem alarak zaman içerisinde tehditlerden fırsat yaratma imkanı bulabilmektedirler.
Örneğin; sosyal medyanın sürekli takip gerektirmesinin farkında olan bir işletme bunun sağlanabilmesi için gerekli koşulları oluşturmak için çaba göstermektedir. Bu da o tehdit unsurundan, minimum düzeyde yara almasını sağlamaktadır.

SWOT analiziyle işletmeler hem genel bir süreç analizi hem de firma özelinde bir analiz yapabilmektedir. Bunu hayata geçiren bir işletme, bulunduğu sektör, pazar payı, rekabet gibi unsurları dikkate alarak bir SWOT analizi oluşturabilir. Böylelikle, kendisinin bulunduğu yeri güçlü yönlerini sıralayarak görebilmektedir. Güçlü olduğu yönleri görebilen bir işletme özellikle rekabete karşı elindeki kozlarında farkına varabilmektedir. Bununla birlikte; zayıf yönlerinin farkına varan işletme bu yönlerini nasıl geliştirmesi gerektiği ile ilgili bir analiz yapar ve zayıf yönlerini, güçlü yönlere çevirmeyi başarabilir.

Sosyal medyayı aktif olarak kullanan ya da kullanacak olan bir işletme, öncelikli olarak SWOT analizi yaparlarsa, kriz süreci için plan hazırlama yolunda bir fizibilite çalışması yapmış sayılabilir. İşletmeler, SWOT analizi ile birlikte işletme, hem kendini hem de çevresini analiz etme imkanı bulabilmektedir. 


\section{SONUÇ}

Araştırma kapsamında, literatür incelenmiş ve SWOT analizi yoluyla sosyal medyada yer alan yaşanmış kriz örneklerinin incelenmiş ve kriz sürecini yönetmeye yönelik ortak faktörler elde edilmeye çalışılmıştır. Yapılan bu araştırma kapsamında elde edilen veriler ışığında sosyal medyada etkili bir kriz yönetmek için elde edilen bulgular ile oluşturulan model aşağıdaki şekildedir:

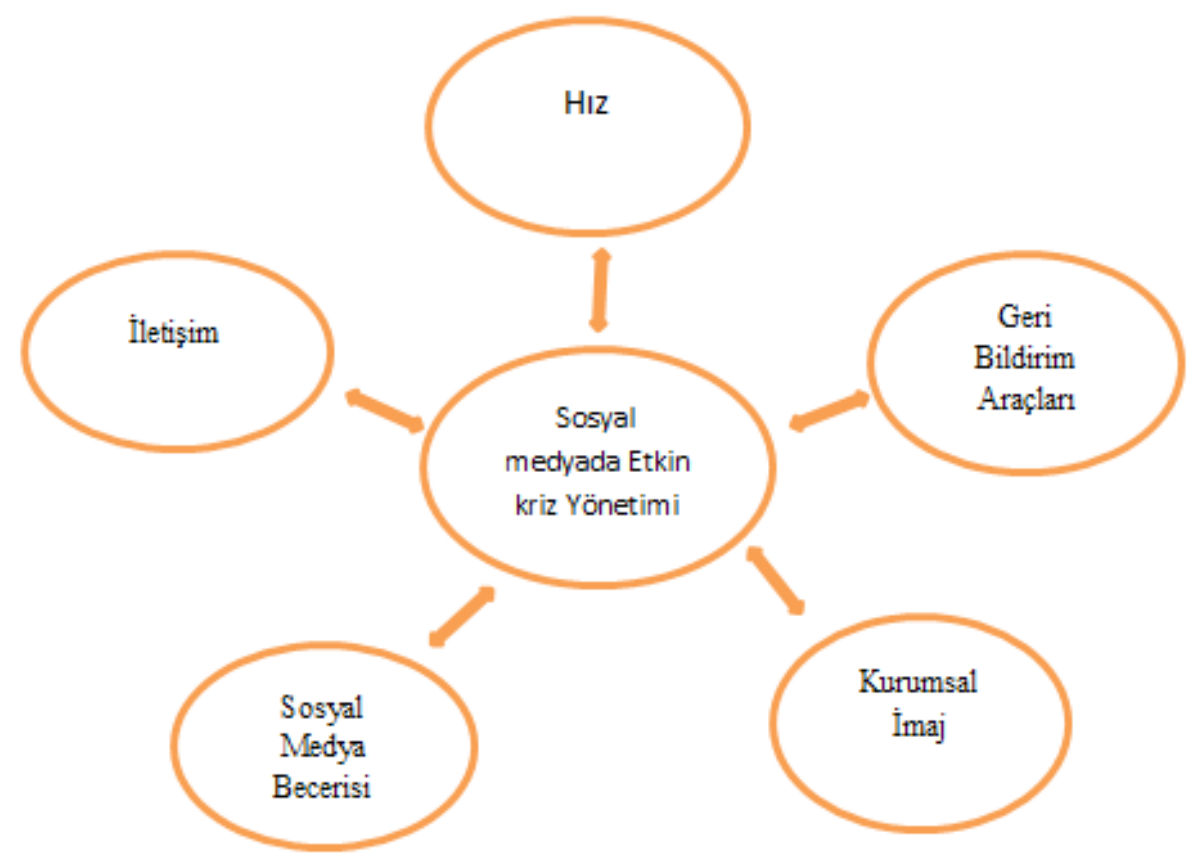

Şekil 2: Sosyal Medyada Etkin Kriz Yönetimini Etkileyen Faktörler

Şekil-2' de görüldüğü üzere, etkili kriz yönetimi için 5 faktör elde edilmiş ve bu faktörler arasındaki ilişkinin etkileşim sağması gerektiği vurgulanarak, ilişki okları çift yönlü olarak gösterilmiştir. Ekonomik yaşamda gerçekleşmiş krizlerin incelenmesi sonucu, firmalar için etkin kriz yönetiminde en önemli unsurun hız olduğu ortaya çıkmıştır. Kriz yönetiminde en öncelikli yapılması gereken işin "hızlı davranmak" olduğu anlaşılmıştır. Sosyal medyada meydana gelen herhangi bir kriz saatler içinde binlerce kişiye ulaşma özelliği göstermektedir. Bu durumda yapılan geri dönüşün hızıı olması kadar, tüm sosyal medya araçlarının aynı anda ve etkinlikte kullanılması ve yapılan geri dönüşün sosyal medya alanında uzman kişilerden yardım alınarak yapılması gerektiği de gözardı edilmemesi gereken önemli bir konudur. Kuşkusuz yapılan her yanlış hareket kurum imajını yerle bir edebileceği gibi, yapılan her doğru hareket kurum imajına da katkıda bulunacaktır. Buradan sosyal medya üzerinden yönetilen krizlerin yönetim sürecindeki her adımının ne kadar önemli olduğu ortaya çıkmaktadır. Bu bağlamda, sosyal medyada bulunan işletmelerin, krizler başlamadan önce gerekli önlemleri alması ve kriz durumlarına hazırlıklı olması gerekmektedir. Krizlerin ne kadar süreceği, krizin sebebine ve iyi yönetilip yönetilmediğine bağlıdır. Krizler ne kadar iyi yönetilirse o kadar hızlı toparlanma sürecine girilmektedir.

Sınırlı imkanlarla yapılan bu araştırmada gerçek yaşamda gerçekleşmiş ancak sekiz kriz vakası incelenebilmiştir. Daha kapsamlı projelerle incelemeye konu kriz vaka sayısı daha da arttırılarak olaylar arasındaki benzerlik ve farklılıklar sektör, faaliyet alanı, işletme büyüklüğü, çalışan sayısı, gibi çeşitli faktörlere göre incelenerek nitel araştırma tekniklerine dayalı istatistiksel analizlerle daha da güvenilir sonuçlar elde edilebilir. Bu yolla ulaşılan sonuçlarla taraflara krizlerle mücadelede sosyal medya kullanımıyla ilgili daha güvenilir rasyonel çözüm önerilerinin getirilebileceğini belirtmeliyiz. 


\section{KAYNAKÇA}

Ada, S. ve Abul, A. (2014); İşletmelerde Sosyal Medya Kullanımı: Işletme Bölümü Öğrencilerinin Algıları Üzerine Bir Araştırma, Kahramanmaraş Sütçü İmam Üniversitesi İktisadi ve İdari Bilimler Dergisi, Cilt:4, Sayı:1, Sf.: 316- 326).

Aktan, C. (2006), Organizasyonlarda Yanlış Uygulamalara Karşı Bir Sivil Erdem, Ahlaki Tepki Ve Vicdanı Red Davranışı: Whistleblowing, Mercek Dergisi, Ekim 2006.

Alexander, D. E. (2014). Social media in disaster risk reduction and crisis management. Science and Engineering Ethics, 20(3), 717-733.

Andrews, S., Gibson, H., Domdouzis, K., \& Akhgar, B. (2016). Creating corroborated crisis reports from social media data through formal concept analysis. Journal of Intelligent Information Systems, 1-26.

Bat, M., ve Yurtseven, Ç. T. (2014). Sosyal Medyada Kurumsal Kriz Yönetimi: Onur Air Örneği. Gumushane University e-Journal Of Faculty Of Communication, 2(3).

Bonsón, E., Flores, F., (2011),"Social media and corporate dialogue: the response of global financial institutions", Online Information Review, Cilt: 35, Sf. $34-49$.

Diyadin, A. (2015), "Etkin Kriz Yönetiminde Sosyal Medyanın Rolü ve Önemi", Yayınlanmış Yüksek Lisans Tezi, Celal Bayar Üniversitesi İktisadi ve İdari Bilimler Fakültesi, Manisa.

Diyadin, A., Özdil, T. (2017), "Etkin Kriz Yönetiminde Sosyal Medyanın Rolü ve Önemi", Lap- Lambert Akademik Yayınları.

Do, H., Ko, E., Woodside, A.,G., (2015) Tiger Woods, Nike, and I are (not) best friends: how brand's sports sponsorship in social-media impacts brand consumer's congruity and relationship quality, International Journal of Advertising, Sf. 658-677.

Graham, M. W., Avery, E. J., \& Park, S. (2015). The role of social media in local government crisis communications. Public Relations Review, 41(3), 386394.

Greer, C. F., \& Ferguson, D. A. (2011), Using Twitter for promotion and branding: A content analysis of local television Twitter sites. Journal of Broadcasting \& Electronic Media, 55(2), 198-214.

Gruber, D. A., Smerek, R. E., Thomas-Hunt, M. C., \& James, E. H. (2015). The real-time power of Twitter: Crisis management and leadership in an age of social media. Business Horizons, 58(2), 163-172.
He, W., Wang, K.F., Chen, Y., Zha, S., ( 2015), An Exploratory İnvestigation of Social Media Adoption by Small Businesses, James Madison University, Harrisonburg, VA 22807, USA.

Hsu, L., \& Lawrence, B. (2016). The role of social media and brand equity during a product recall crisis: $A$ shareholder value perspective. International Journal of Research in Marketing, 33(1), 59-77.

Humphreys, L., Wilken, R., (2014), Social Media, Small businesses and the Control of Information, Information, Communication \& Society, Cilt: 18, Sayı: 3, Sf. 295-309).

Jones, N., Borgman, R., Ulusoy, E., (2015),"Impact of social media on small businesses", Journal of Small Business and Enterprise Development, Cilt. 22, Sf. 611 $-632$.

Jong, W., \& Dückers, M. L. (2016), Self-correcting mechanisms and echo-effects in social media: An analysis of the "gunman in the newsroom" crisis. Computers in Human Behavior, 59, 334-341.

Kara, T., (2012), Sosyal Medya Üzerinde Yeni Nesil Pazarlama ve Türkiye Bilgi \& İletişim Hizmetleri Endüstrisinde Sosyal Ağların Kullanımına Yönelik Bir Araştırma, Global Media Journal, Cilt:2, Sayı:4, Sf. : 102-118.

Kim, S., Zhang, X. A., \& Zhang, B. W. (2016). Selfmocking crisis strategy on social media: Focusing on Alibaba chairman Jack Ma in China. Public Relations Review.

Lin, X., Spence, P. R., Sellnow, T. L., \& Lachlan, K. A. (2016). Crisis communication, learning and responding: Best practices in social media.Computers in Human Behavior.

Maresh-Fuehrer, M. M., \& Smith, R. (2016). Social media mapping innovations for crisis prevention, response, and evaluation. Computers in Human Behavior, 54, 620-629.

Omilion-Hodges, L. M., \& McClain, K. L. (2016). University use of social media and the crisis lifecycle: Organizational messages, first information responders' reactions, reframed messages and dissemination patterns. Computers in Human Behavior, 54, 630-638.

Peltekoğlu, F.B., Hürmeriç, P., (2012), Social Media Used As A Marketing Public Relation Tool In Turkish Football Teams, Selçuk İletişim, Sf. : 5-13.

Ryschka, A. M., Domke-Damonte, D. J., Keels, J. K., \& Nagel, R. (2016). The Effect of Social Media on Reputation During a Crisis Event in the Cruise Line 
Industry. International Journal of Hospitality \& Tourism Administration, 17(2), 198-221.

Susarla, A., Oh, J. H., \& Tan, Y. (2016). Influentials, imitables, or susceptibles? Virality and word-ofmouth conversations in online social networks. Journal of Management Information Systems, 33(1), 139-170.

Wang, W.Y.C., Pauleen, D.J., Zhang, T., ( 2015), How Social Media Applications Affect B2b Communication And İmprove Business Performance In Smes, Industrial Marketing Management, sf.: 11.
Wang, Y. (2016). Brand crisis communication through social media: A dialogue between brand competitors on Sina Weibo. Corporate Communications: An International Journal, 21(1), 56-72.

Yoo, E., Rand, W., Eftekhar, M., \& Rabinovich, E. (2016). Evaluating information diffusion speed and its determinants in social media networks during humanitarian crises. Journal of Operations Management.

Zhao, L., Yin, J., \& Song, Y. (2016). An exploration of rumor combating behavior on social media in the context of social crises. Computers in Human Behavior, 58, 25-36. 